Otto Kahn-Freund

\title{
Autobiographische Erinnerungen an die Weimarer Republik. \\ Ein Gespräch mit Wolfgang Luthardt
}

Einleitung

Das im folgende abgedruckte Interview wurde im Februar 1978 mit Sir Otto Kahn-Freund, O. C., F. B. A., emeritierter, ordentlicher Professor der Rechtswissenschaft an der Universität von Oxford, in Haslemere, England, geführt. Otto Kahn-Freund, geboren am r7. November 1900 in Frankfurt, gestorben am r6. August 1979 im zur zweiten Heimat gewordenen England, gehörte einer Generation deutscher Wissenschaftler an', für die die Machtergreifung des Nationalsozialismus r 933 einen endgültigen Bruch mit dem damaligen Deutschland markierte. Wie viele andere vertriebene Wissenschaftler erhielt er entscheidende Prägungen durch die sozialdemokratische Arbeiterbewegung in der Weimarer Zeit. Als Jurist wurde er vor allem durch den bedeutenden Arbeitsrechtler Hugo Sinzheimer ${ }^{2}$ beeinflußt: Ein Einfluß, der, wie er es selbst formulierte, sein gesamtes wissenschaftliches Wirken nachhaltig und durchgängig bestimmt hat.

Vor 1933 arbeitete Otto Kahn-Freund als Vorsitzender Richter an einem Arbeitsgericht in Berlin. Während dieser Zeit beschäftigte er sich wesentlich publizistisch mit arbeitsrechtlichen Sachverhalten. Seine juristische Dissertation über: „Umfang der normativen Wirkung des Tarifvertrages und Wiedereinstellungsklausel " (1925), veröffentlicht Berlin, 1928, fertigte er bei Hugo Sinzheimer an. Daneben erfolgte eine Vielzahl kleinerer Studien und ausführlicher Buchbesprechungen in den Zeitschriften "Arbeitsrechts-Praxis«, »Soziale Praxis«, »Die Gesellschaft«, "Arbeitsrecht « und »Juristische Wochenschrift«. Bekannter geworden sind seine Studien »Das soziale Ideal des Reichsarbeitsgerichts « (193I) und »Der Funktionswandel des Arbeitsrechts ", $1932 \mathrm{im}$ »Archiv für Sozialwissenschaft und Sozialpolitik « erschienen. Wohl aufgrund gerade der beiden letzten Arbeiten boten ihm, unabhängig voneinander, der Arbeitsrechtler Walter Kaskel und der sozialdemokratische Staatsrechtslehrer Hermann Heller die Möglichkeit der Habilitation an. Das nationalsozialistische Regime entfernte ihn, vermittelt über das »Gesetz zur Wiederherstellung des Berufsbeamtentums « vom 7. April I 933, aus dem Amt. Im Juni 1933 mußte er in größter Gefahr zusammen mit seiner Frau Elisabeth Deutschland verlassen.

Otto Kahn-Freund und seine Frau immigrierten nach England. An der London School of Economics and Political Science (LSE) begann er das Studium des

\footnotetext{
I Aus der Literatur zur Emigration deutscher Wissenschaftler vgl. u. a. Helge Pross, Die deutsche akademische Emigration nach den Vereinigten Staaten 1933-1941, Berlin 1955; ferner die Selbstdarstellungen deutscher Emigranten in: Hermann Kesten (Hrsg.), Ich lebe nicht in der Bundesrepublik, München 1964 und die Interviews in: Matthias Greffrath (Hrsg.), Die Zerstörung der Vernunft, Reinbek/Hamburg 1979. Franz Neumann, Intellektuelle Emigration und Sozialwissenschaft (1952), in: Ders., Wirtschaft, Staat, Demokratie, 1978, stellt eine oklassische Analyse dieser Problematik dar.

$2 \mathrm{Zu}$ Sinzheimer siehe vor allem die Einleitung von Otto Kahn-Freund zur Edition der Arbeiten in »Arbeitsrecht und Rechtssoziologie «; die Würdigung durch Kahn-Freund in: FAZ, 24. Mai 1975; die Besprechung der 1977 nachgedruckten frühen Werke durch Kahn-Freund in: NJW 1978, H. 8, 363 f.; M. Martiny, Integration oder Konfrontation, I 976 , s s ff.; W. Luthardt, in: KJ 4/1977, 443 ff.; S. Miller, Die Bürde der Macht, 1978, 293 f,, $307 \mathrm{ff}$

3 Vgl. hierzu F.(riedrich) A. (ugust) Hayek, The London School of Economics r 895-r945, in: Economica, Feb. 1946, pp. I-31.
} 
englischen Rechts. Aus dieser Zeit datiert auch seine langjährige Freundschaft mit Harald J. Laski ${ }^{4}$, einem der bedeutendsten sozialistischen Theoretiker und Politiker. An der LSE erhielt er 1935 eine assistant lectureship, danach eine lectureship, 1947 eine readership und erst im Jahre I95 I einen Lehrstuhl für Law.

Im Jahre 1964 wurde er dann, bis zu seiner Emeritierung im September 1971, Lehrstuhlinhaber für Comparative Law an der Universität Oxford. In den dreißiger und vierziger Jahren nahm er engagiert in Vorträgen, gehalten vor Gewerkschaftsgruppen, Stellung zum Nationalsozialismus, zu einer Neustrukturierung Europas sowie zur Problematik eines »Neuen Deutschland «s. In den fünfziger, sechziger und siebziger Jahren beschäftigte sich Otto Kahn-Freund einerseits ausführlich und differenziert mit dem englischen Recht, andererseits trat parallel dazu verstärkt der vergleichende Aspekt in den Mittelpunkt seiner umfangreichen Analysen. Die Ubersetzung seiner Studie „Labour and the Law « ins Deutsche - durch Franz Mestitz - im Jahre 1979 sowie die demnächst erscheinende Úbersetzung seiner British Academy lectures »Heritage and Adjustment « (1979) - ebenfalls durch Franz Mestitz - zeigen an, daß die Bedeutung der von Otto Kahn-Freund vorgelegten Arbeiten erkannt worden ist. Die Mitgliedschaft in internationalen Vereinigungen (z. B. "International Law Society «) wie auch seine Mitarbeit als Experte für internationale Gewerkschaftsorganisationen war die konsequente Frucht einer wissenschaftlichen Tätigkeit, in deren Mittelpunkt immer wieder rechtliche, soziale und politische Sachverhalte der abhängigen Arbeit gestanden haben.

Im Interview selbst kommen überwiegend Probleme der Weimarer Republik zur Sprache. Otto Kahn-Freund hatte sich selbst engagiert als Arbeitsrechtler an der zeitgenössischen Diskussion beteiligt. Seine Arbeiten "Das soziale Ideal des Reichsarbeitsgerichts « (1931) und der Aufsatz "Der Funktionswandel des Arbeitsrechts" (1932) gehören heute in der wissenschaftlichen Diskussion über die Zerstörung des wesentlich von sozialdemokratischer und gewerkschaftlicher Seite konstituierten "Kollektiven Arbeitsrechts " zur Standardliteratur. In diesem Zusammenhang ist es ein bleibendes historisches Verdienst von Thilo Ramm, durch die Edition ("Arbeitsrecht und Politik ", 1966) dieser Arbeiten sowie den systematischen Verweis ${ }^{6}$ eine seitdem bemerkenswerte Rezeption? in der Literatur wesentlich mit initiiert zu haben.

Wolfgang Luthardt

4 Zu Laski siehe den Nachruf von George Catlin, Harold Laski, „Das Gewissen« der Labour Party, in: Frankfurter Hefte, Jg. 5, H. 7, Juli 1950, S. 700 f.

s Vgl. hierzu die in der Kurzbibliographie angeführten Titel sowie: Otto Kahn-Freund, The Weimar Constitution, in: The Political Science Quarterly, Vol. XV, I944, No. I-4, $229 \mathrm{ff}$. Zur Sache selbst auch: Thilo Ramm, Otto Kahn-Freund und Deutschland, in: F. Gamillscheg u. a. (Hrsg.), Gedächtnisschrift für Otto Kahn-Freund, München 1981 , XXI ff. (XXIX ff.).

$6 \mathrm{Vg}$. Th. Ramm, in: KJ, H. 2/1968, ro8 ff. ( ( I 4 ); ders., Einführung in das Privatrecht, 3 Bde., I970, Bd. I, $\mathrm{G} 77, \mathrm{~L} 268$.

7 Vgl.u. a. R. Hoffmann, Rechtsfortschritt durch gewerkschaft liche Gegenmacht, 1968, 97; L. Unterseher, in: KJ 2/1968, 95 ff.; H. H. Hartwich, Arbeitsmarkt, Verbände und Staat 1918-1933, 1967; L. Unterseher, Arbeitsvertrag und innerbetriebliche Herrschaft, 1969; W. Rosenbaum, Naturrecht und positives Recht, 1972, 83; W. Däubler, Das Grundrecht auf Mitbestimmung, 1973, 151 ; ders., Gesellschaftliche Interessen und Arbeitsrecht, 1974, 22; J. Perels, Kapitalismus und politische Demokratie, 1973, 50 ff.; X. Rajewski, Arbeitskampfrecht in der Bundesrepublik, 1970, I4 ff.; H. H. Hartwich, in: G. Doeker / W. Steffani (Hrsg.), Klassenjustiz und Pluralismus, 1973 , 13 I ff. (14 I ff.); die Beiträge von R. Hoffmann, W. Däubler, H. H. Hartwich, in: M. Kittner (Hrsg.), Streik und Aussperrung, I 974; B. Blanke / U. Jürgens / H. Kastendiek, in: Prokla Nr. $14 / \mathrm{I}$, 2974 , 5 I ff. $(98$ f.); T. W. Mason, in: H. Mommsen / D. Petzina / B. Weisbrod (Hrsg.), Industrielles System und politische Entwicklung in der Weimarer Republik, 1974, 322 ff. (344 f.); U. Wesel, in: Kursbuch, Nr. 40/1975, 77 ff. (98); W. Luthardt, in: KJ 3/1975, 326 ff. (329); ders., in: O. Kirchheimer, Von der Weimarer Republik zum Faschismus, 1976, 7 ff. (27); ders., in: KJ 4/1977, 443 ff., (449); Th. Blanke / R. Erd / U. Mückenberger / U. Stascheit (Hrsg.), Kollektives Arbeitsrecht, 2 Bde., 1975, Bd. 1, I 50; R. Wahsner, in: KJ 4/1974, 369 ff. $(372,375)$; I. Maus, Bürgerliche Rechtstheorie und Faschismus, 1976,60 , 143; U. Mayer, Paritätische Mitbestimmung und Arbeitsver- 
LUTHARDT: Welcher Familie entstammen Sie? Bestand bei Ihnen von vornherein ein besonderes Interesse, Rechtswissenschaft $z$ u studieren?

KAHN-FREUND: Ich komme aus einer jüdischen, bürgerlichen Familie, bin in normaler Weise in die Schule gegangen, und zwar in ein Gymnasium in Frankfurt, bis ich im Jahre 1918 zum Militär einberufen wurde. Ich diente noch ungefähr sechs Monate in der Armee, bin aber nicht mehr an die Front gekommen und nahm dann das Studium im Winter I9r8/19 auf. Ursprünglich hatte ich keine Absicht, Rechtswissenschaft zu studieren, sondern aufgrund meiner Interessen schon in der Schule hatte ich beschlossen, Geschichte zu studieren. Meine Interessen waren nicht sehr scharf definiert, zielten jedoch wesentlich auf die mittelalterliche Geschichte. Im Verlauf meines historischen Studiums in Frankfurt, Heidelberg und in Leipzig habe ich dann festgestellt, daß ich mich eigentlich nicht zum Historiker, sondern besser zum Juristen eigne. Es war vielleicht auch der Einfluß meines häuslichen Milieus meine Eltern wollten gerne, daß ich Jurist würde - und auch der Einfluß meiner Freunde, zu denen z. B. Ernst Fraenkel ${ }^{x}$ gehörte. So wurde ich dann Jurist, jedoch immer mit einem Schlag historischen Interesses.

LUTHARDT: Wann baben Sie Hugo Sinzheimer kennengelernt? Hatten Sie zu ihm schon Kontakte, als er während der "Novemberrevolution" für kurze Zeit in Frankfurt Polizeipräsident war?

KAHN-FREUND: Wie ich Sinzheimer ${ }^{2}$ kennengelernt habe, ist mir unvergeßlich. Im Sommer 1917 war im Ostpark in Frankfurt eine große Demonstration, und zwar eine Demonstration sowohl der sozialdemokratischen als auch der Demokratischen Partei zur Zeit der sog. Friedensrevolution ${ }^{3}$ des Reichstags vom Juli 1917. Es waren sechs oder sieben Redner anwesend. Einer dieser Redner war Sinzheimer. Damals sah ich ihn zum ersten Male. Ich war noch nicht siebzehn. Er hat mich einfach überwältigt. Er war ein glänzender Redner. Ich wußte immerhin schon genug und hatte auch genug gelesen, um sofort an Lassalle zu denken, mit dem er eine gewisse Ähnlichkeit hat - und auch wiederum eine große Verschiedenheit. Aber jedenfalls, Sinzheimer hat mich stark beeindruckt. Dies ist für mich unvergeßlich, ich sehe es heute und ich höre ihn noch: Friede, Freiheit, Brot. So etwas kann man nicht vergessen. Ich besuchte dann die Universität und dort hielt Sinzheimer ein Seminar über Arbeitsrecht. Natürlich bin ich zu ihm gegangen. Das verstand sich einfach von

hältnis, 1976, 62, 87; M. Martiny, Integration oder Konfrontation, 1976, ${ }_{333}$ ff.; H. H. Wohlgemuth, Staatseingriff und Arbeitskampf, 1977, 33 ff.; K. Ortwein, in: R. Kühnl/ G. Hardach (Hrsg.), Die Zerstörung der Weimarer Republik, I977, 214 ff.; H. Ridder, in: Leviathan, $4 / 1977,467$ ff. (488f.); V. Bahl, in: GMH, 7/1978, 397 ff.; H. Kremendahl, Pluralismustheorie in Deutschland, 1977, 172 f.; S. Schönholz, Grenzen der Regelung individueller Arbeitsbeziehungen durch Recht, IIM/dp 79-59, 57; U. Reifner, Gewerkschaftlicher Rechtsschutz, IIM-dp/79-104, 74, I54 ff.; U. Mückenberger, in: BLStSozArbR, H. I6/17, I980, 24I ff., 257 ff. (257, 26I); A. Kaiser, in: DuR, $4 / 1980,444$ ff. (448 f.); zuletzt die beiden Beiträge von Th. Ramm in: Gedächtnisschrift für Otto Kahn-Freund; F. Mestitz, in: ZfNRG, Jg. 1980,47 ff. $(65)$.

I Fraenkel, Ernst (1898-1975); Rechtsanwalt, Assistent bei Hugo Sinzheimer; Dozent an der Akademie der Arbeit in Frankfurt; Dozent an der Gewerkschaftsschule des Deutschen Metallarbeiterverbandes in Bad Dürrenberg; Syndikus des Deutschen Metallarbeiterverbandes; Rechtsberater des Parteivorstandes der SPD vor I933; Emigration 1938 in die USA, Beratertätigkeit für die amerikanische Regierung in Korea; 1953 bis 1967 o. Professor für Politische Wissenschaft an der FU Berlin.

2 Sinzheimer, Hugo (1875-1945); Rechtsanwalt, Mitbegründer der Akademie der Arbeit in Frankfurt; Professor für Arbeitsrecht an der Universität Frankfurt; 1918/19 Polizeipräsident in Frankfurt; Räteexperte der Mehrheitssozialdemokratie; Mitglied der verfassungskonstituierenden Nationalversammlung; Mitverfasser der Weimarer Verfassung; führender sozialdemokratischer Arbeitsrechtler; 1933 Emigration nach Holland; Professor für Arbeitsrecht und Rechtssoziologie in Amsterdam und Leyden.

3 Die Friedensresolution des Reichstages, wesentlich auf die Initiative von Matthias Erzberger zurückgehend, wurde am I9. Juli 1917 von den drei Mehrheitsparteien Zentrum, Fortschrittliche Volkspartei und Mehrheitssozialdemokratie angenommen. In ihr kam die Tendenz zum Vorschein, in etwa den Status quo zu erhalten. 
selbst. Ich habe dort dann ein Referat gehalten. Später wurde ich Assistent bei ihm, das war viel später, sowohl in der Universität als vor allem auch in seiner Praxis. Während der Revolution hatte ich keine Kontakte zu ihm. Ich war gerade eben ein Student, während Sinzheimer damals ein bedeutender Zeitgenosse gewesen war. Er war Polizeipräsident usw.

LUTHARDT: Waren Sie selbst auch, wie z. B. Ernst Fraenkel, in einem Arbeiterund/oder Soldatenrat nach 1918 tätig gewesen?

KAHN-FREUND: Ich war nicht in einem Arbeiter- oder Soldatenrat aktiv tätig. Ich war überhaupt politisch nicht sehr engagiert. Die Grenzen, in denen ich engagiert war, kann ich Ihnen gleich umreißen.

LUTHARDT: Wann ungefäbr und unter welchen Umständen haben Sie Fraenkel, Franz Neumann und Otto Kirchheimer kennengelernt?

KAHN-FREUND: Ich habe mir überlegt, wann ich eigentlich Ernst Fraenkel kennengelernt habe. Es ist wahrscheinlich, daß ich ihn schon in Frankfurt kannte, wo wir beide Studenten waren. A ber nicht gut. Entscheidend für unser Zusammentreffen war unser gemeinsames Studium in Heidelberg, und zwar war dies im Sommersemester 1919. Wir wurden sehr enge Freunde. Und er hat auf mich einen starken Eindruck gemacht. Er war nicht nur zwei Jahre älter als ich, sondern - was natürlich entscheidend war - er war wirklich im Krieg gewesen. Franz Neumann ${ }^{4}$, den ich niemals so gut kannte wie Fraenkel, begegnete ich wohl schon in Frankfurt. Er war auch ein Schüler von Sinzheimer, eine Zeitlang dessen Assistent und gehörte zu demselben Kreis. Otto Kirchheimer's hatte mit diesem Kreis nichts zu tun. Erst einmal war er jünger. Ich lernte ihn wahrscheinlich erst in Berlin kennen, am Ende der zwanziger Jahre.

LUTHARDT: Sie sagen also, daß Sie zu Sinzheimer während der Revolution keine weiteren Kontakte hatten. Ich habe die Frage aus dem Grunde formuliert, weil Neumann 1952 einmal einen Aufsatz ${ }^{6}$ verfaßte ...

KAHN-FREUND: Ich erinnere mich nicht mehr an die Einzelheiten, aber an die Stimmung. Wir waren ja alle blind. Die ganzen Vorgegebenheiten des Nationalsozialismus waren schon unmittelbar angelegt. Es existierte eine sehr starke völkische Studentenbewegung 7 , der Antisemitismus war virulent ${ }^{8}$ und Sinzheimer scharfen Angriffen ausgesetz $t^{9}$. An die Vorgänge, bei denen seine Vorlesungen gestört wurden, erinnere ich mich nicht - Fraenkel ist in seiner Erinnerungsskizze ${ }^{10}$ darauf eingegangen. $\mathrm{Daß}$ aber die Stimmung außerordentlich gespannt war, unterliegt keinem Zweifel. Und sie war es in Frankfurt, in Heidelberg dann noch mehr, im

\footnotetext{
4 Neumann, Franz (1900-1954); Rechtsanwalt; Assistent bei Sinzheimer; Dozent an der Akademie de Arbeit und an der Deutschen Hochschule für Politik in Berlin; Syndikus des Deurschen Baugewerksbundes; Rechtsberater des Parteivorstandes der SPD; Richter am preußischen Landgericht mit Sitz in Frankfurt/Main; Emigration 1933 nach London; Studium der Political Science an der London School of Economics and Political Science; Mitarbeiter des Instituts für Sozialforschung; Ubersiedlung in die USA Mitarbeiter im Office of Strategic Services; Berater der amerikanischen Regierung; o. Professor für Politische Wissenschaft an der Columbia University.

s Kirchheimer, Otto (1905-1965); jüngerer sozialdemokratischer Verfassungsrechtler und -theoretiker in der Weimarer Republik; Emigration 1933 nach Paris; dort Mitarbeit am Institut für Sozialforschung; 937 Auswanderung in die USA; wiss. Berater im US Department of State; o. Professor für Politische Wissenschaft an der New School for Social Research in New York und an der Columbia University.

$6 \mathrm{VgJ}$. Neumann, Intellektuelle Emigration und Sozialwissenschaft, in: ders., Wirtschaft, Staat, Demokratie, $1978,402 \mathrm{ff}$.

7 Vgl. G. L. Mosse, Ein Volk - Ein Reich - Ein Führer, 1979, 205 ff., 28 r ff.

8 Vgl. ebda., 309 ff. Ferner die entsprechenden Passagen in: Leo Löwenthal, Mitmachen wollte ich nie. Ein autobiographisches Gespräch mit $\mathrm{H}$. Dubiel, 1980.

$9 \mathrm{Vgl}$. Neumann, Intellektuelle Emigration, ..., a. a. O., 4 r $2 \mathrm{f}$

10 Ernst Fraenkel, Hugo Sinzheimer, in: ders., Reformismus und Pluralismus, 1973, $131 \mathrm{ff}$.
} 
Grunde genommen überall. Man ist in der ganzen Weimarer Republik niemals darüber hinweggekommen.

LUTHARDT: Haben Sie sich auch wäbrend Ibrer Studienzeit in einem sozialistischen Studentenbund organisiert?

KAHN-FREUND: Ja, ich war eine Zeitlang Mitglied sozialistischer Studentengruppen. Ich war immer weniger politisch aktiv als Neumann oder Fraenkel zu dieser Zeit. Ich stand auch politisch - soweit man das definieren kann - wahrscheinlich weiter »rechts « als Fraenkel und Neumann zu der damaligen Zeit. Fraenkel war Marxist, das war ich eigentlich nie. Ich habe natürlich sozialdemokratisch gewählt und war Mitglied der Sozialdemokratischen Partei. In Frankfurt und später auch in Berlin habe ich mich stets in diesen halb-politisch/akademischen Zirkeln bewegt. Meine Frau auch, wir haben uns dort kennengelernt.

LUTHARDT: Welche Arbeiten sozialdemokratischer Autoren haben Sie besonders beeinflußt. Hilferdings "Finanzkapital*, Renners *Rechtsinstitute*, Sinzheimers Arbeitsrecht $\propto$ ?

KAHN-FREUND: Hilferdings "Finanzkapital ${ } "$ hatte auf mich eigentlich nur einen indirekten Einfluß. Ich habe es eigentlich nie richtig gelesen, aber natürlich sind die Ideen durchgesickert. Hingegen haben die beiden anderen Bücher, von denen Sie sprechen, einen starken Eindruck auf meine gesamte geistige Entwicklung ausgeübt. Dies gilt vor allem selbstverständlich für die Arbeiten von Sinzheimer, nicht nur die "Grundzüge des Arbeitsrechts«, die Sie erwähnen, sondern auch die früheren Werke, die jetzt wieder nachgedruckt wurden. Und natürlich auch Renners »Rechtsinstitute ${ }^{12}$. Ich habe Sie ja hier herausgegeben.

$\mathrm{Zu}$ dem Einfluß, den Sinzheimer auf mich ausgeübt hat, möchte ich Ihnen noch einiges mitteilen. Ich habe im Verlauf der letzten Jahre aus verschiedenen Gründen so ziemlich alles wieder gelesen, was Sinzheimer geschrieben hat. Teilweise, weil ich diese kleinen Schriften mitherausgegeben habe, teilweise auch, weil die früheren Arbeiten wieder erschienen sind. Dabei habe ich festgestellt, daß viele der Ideen, die ich hier in England entwickelt habe, z. B. in meinem Buch über das Arbeitsrecht, im Grunde genommen von Sinzheimer her kommen. Sinzheimer hat also auf mich einen viel stärkeren Einfluß ausgeübt, als ich früher angenommen habe. Vor allem seine im Grunde genommen pluralistische Einstellung - Sinzheimer war ja kein "richtiger « Marxist $^{13}$. Er wahr stark beeinflußt von Marx, wie wir alle. Und diese Haltung von Sinzheimer ist auf mich übergegangen. Insbesondere auch jene Aussagen über Macht und Recht hatten einen nachhaltigen Eindruck auf mich. Hinzufügen möchte ich noch, daß gleichfalls die Rennersche marxistische Analyse des Eigentumsbegriffs, auch des Vertragsbegriffs, der bei Renner etwas zu kurz kommt, mich bis heute, zum Teil, ohne daß ich mir immer dessen bewußt war, durchaus geprägt hat, obwohl ich selbst kein Marxist bin.

LUTHARDT: Gebörten Sie auch dem Berliner *Kreis* an, von dem Fraenkel in seinem Vorwort zum Neudruck verschiedener Arbeiten 1968 spricht $^{14}$ ?

KAHN-FREUND: Ich war im Jahre 1927 und 1928 in England und Amerika. Ich komme mütterlicherseits aus einer internationalen Familie. Und das hat sich später als wichtig erwiesen. Von 1928 bis 1933 bin ich dann in Berlin. Dort gehörte ich zu jenem

I I Rudolf Hilferding. Das Finanzkapital (1910), Frankfurt 1973 (3).

I 2 Karl Renner, Die Rechtsinstitute des Privatrechts (1904), Tübingen 1929 (2). Otto Kahn-Freund besorgte 1949 eine englische Ausgabe. Die Übersetzung von Einleitung und umfangreichen Anmerkungen nebst Veröffentlichung erfolgte Stuttgart 196s.

13 Vgl. Ernst Fraenkel, Rätemythos und soziale Selbstbestimmung, in: ders., Deutschland und die westlichen Demokratien, $1974,69 \mathrm{ff}$.

I4 Fraenkel, Vorwort zum Neudruck, in: ders., Zur Soziologie der Klassenjustiz und Aufsätze zur Verfassungskrise I93 I-32, $x 968$, VII ff. 
Kreis, der u. a. aus den Suhrs's, den Flatows ${ }^{16}$, Fraenkels und Franz Neumann und seiner damaligen Frau bestand.

LUTHARDT: War auch für Sie die Möglichkeit von wesentlicher Bedeutung, die konservative Justiz und vor allem die Rechtsprechung mittels einer strikten Bindung an das vom Parlament verabschiedete Gesetz auf die demokratischen Grundnormen der Weimarer Verfassung festzulegen?

KAHN-FREUND: Nun stellen Sie mir eine Gewissensfrage. Das ist die Gewissensfrage an den Juristen. Nämlich über meine Einstellung zu der Bindung des Gerichtes an das Gesetz. Sie wollen wissen, ob ich die Fraenkelsche Einstellung teilte, die in der "Soziologie der Klassenjustiz «"7 zum Ausdruck kommt. Diese Frage ist einfach zu bejahen. Sie war damals zu bejahen, und sie ist auch heute noch zu bejahen. Ich habe im Verlauf der Jahre an der Bejahung dieser Frage viel stärker festgehalten als Ernst Fraenkel. Mit anderen Worten, ich bin ein Positivist. Ich habe gerade den Aufsatz von Franz Neumann über das Naturrecht ${ }^{18}$ wieder durchgesehen. Ich habe dem Naturrecht immer ablehnend gegenübergestanden und tue es auch heute noch. Und zwar aus Gründen heraus, die mit meinen Grundeinstellungen zu tun haben. Die einzig demokratische Hoffnung, die man in der Weimarer Republik haben konnte, wo ja die Justiz politisch verkauft war' ${ }^{19}$ - man kann es nicht anders ausdrücken -, nicht im Geldsinn, sondern im ideologischen Sinn, war natürlich die Bindung des Richters an das Gesetz. Und deswegen stand ich allen übergesetzlichen Rechtsideen mit der striktesten Feindschaft gegenüber wie wir alle. Denken Sie bitte an den Aufsatz von Franz Neumann, den Sie wahrscheinlich kennen, gegen die Uberprüfung der Gesetze durch die Rechtsprechung ${ }^{20}$, das habe ich vollständig unterschrieben. LUTHARDT: Haben Sie sich politisch als Referent in der Arbeiterbewegung betätigt? Konkreter, in den freien Gewerkschaften und in der Bildungsarbeit der Sozialdemokratie?

KAHN-FREUND: Ich war Mitglied der Sozialdemokratischen Partei, habe vielleicht auch ab und an bei der Partei referiert. Ich habe aber nicht systematisch an ihrer Bildungsarbeit teilgenommen, so wie Fraenkel. Hingegen war ich stark in die Bildungsarbeit der Gewerkschaften, sowohl beim $\mathrm{ADGB}^{21}$ als auch bei einzelnen

is Suhr, Otto (1894-1957); als Leutnant Teilnehmer des Ersten Weltkrieges; Nationalökonom; Mitarbeiter der Zentrale für Heimatdienst in Kassel; erster akademisch ausgebildeter lokaler Arbeitersekretär Deutschlands; Dozent an der Wirtschaftsschule des Deutschen Metallarbeiterverbandes in Bad Dürrenberg; Leiter der volkswirtschaftlichen Abteilung des Afa-Bundes in Berlin; Dozent an der Deutschen Hochschule für Politik; nach 1945 alleiniger Vertreter Berlins im Herrenchiemseer Verfassungskonvent; Vertreter Berlins im parlamentarischen Rat; Hauptinitiator der Wiederbegründung der Deutschen Hochschule für Politik in Berlin; Stadtverordnetenvorsteher; Präsident des Abgeordnetenhauses; Regierender Bürgermeister von Berlin.

16 Flatow, Georg; Jurist; Arbeitsrechtler; Referent im preußischen Handelsministerium; Verfasser des wichtigsten, den Gewerkschaften nahestehenden Kommentars zum Betriebsrätegesetz (1920); Hauptinitiator der 1919 gegründeten, jedoch ohne große Relevanz gebliebenen »sozialdemokratischen Juristenvereinigung «, deren von 1924 bis 1933 erscheinende Zeitschrift Recht und Sozialismus « kein wesentlicher Erfolg beschieden war.

17 Fraenkel, Zur Soziologie der Klassenjustiz, Berlin 1927. Abgedruckt in: ders., Reformismus und Pluralismus, 1973, 88 ff.; ders., Zur Soziologie der Klassenjustiz und Aufsätze zur Verfassungskrise.

18 Neumann, Typen des Naturrechts (1940), in: ders., Wirtschaft, Staat, Demokratie, $223 \mathrm{ff}$.

$19 \mathrm{Vgl}$. W. Hoegner, Der politische Radikalismus in Deutschland 1919-1933, 1966, I14 ff.; H. u. E. Hannover, Politische Jusitz 1918-1933, 1966; I. Staff, Justiz im Dritten Reich, 1964, 7 ff.; M. Hirschberg, Das Fehlurteil im Strafprozeß, 1962, I 92 ff. Zeitgenössische Arbeiten sind u. a. Fraenkel, Soziologie der Klassenjustiz; M. Beradt, Der deutsche Richter, Frankfurt 1930, 197 ff.; Hugo Sinzheimer / Ernst Fraenkel, Die Justiz in der Weimarer Republik. Eine Chronik, I968.

20 Neumann, Gegen ein Gesetz zur Nachprüfung der Verfassungsmäßigkeit von Reichsgesetzen, in: Die Gesellschaft, Jg. VI/1929, SI7 ff.

2I ADGB (= Allgemeiner Deutscher Gewerkschaftsbund); Dachorganisation der sozialdemokratisch ausgerichteten Gewerkschaften in der Weimarer Republik (1919-1933). Erster Vorsitzender von 1920-1933 war Theodor Leipart. Theoretisches Organ: „Die Arbeit«; Aktuell-politisches Organ: "Gewerkschafts-Zeitung". 
Gewerkschaften, eingebunden. Ich habe immer wieder beim Deutschen Baugewerksbund $^{22}$ gesprochen und war insbesondere durch die Arbeit an der "Akademie der Arbeit $\ll^{23}$ in Frankfurt, wo ich einige Zeit systematisch unterrichtet habe, mit gewerkschaftlichen Aufgaben usw. vertraut. In dieser Beziehung war ich also engagiert.

LUTHARDT: Hatten Sie Kontakte zum sog. linken Flügel der Partei und der Gewerkschaften?

KAHN-FREUND: Meine Kontakte zum linken Flügel der Partei existierten praktisch nicht. Ich habe mich nie dazu gerechnet. Ich war mir immer klar darüber, daß ich in der Partei weiter rechts stand als Fraenkel oder Neumann, nicht notwendigerweise als Suhr, der wesentlich durch den AfA-Bund ${ }^{24}$ mit der Gewerkschaft verbunden war. Meine Haltung war distanzierter und anders als die von Fraenkel, weniger engagiert, sowohl weltanschaulich-ideologisch-marxistisch als auch vor allem politisch. Es bestand natürlich ein gewisser Kontrast zwischen meinem inneren Engagement und der Festlegung in weltanschaulicher Beziehung bzw. in bezug auf die Tagesereignisse. Ich spreche nicht, wenn ich sage, daß ich distanziert war, von einer Distanzierung meines persönlichen Empfindens, sondern einer Distanzierung meiner intellektuellen Entscheidungen und meines Handelns. LUTHARDT: Aber mußte dies nicht notwendigerweise zu einem Spannungsverbältnis fübren?

KAHN-FREUND: Man kann einen gewissen Widerspruch sehen zwischen der Stellung eines Richters, die ich ja hatte, und der Stellung eines Menschen, der politisch engagiert ist, innerlich zumindest. Das ist aber etwas, was man im damaligen Deutschland nicht gelten ließ. Denn die meisten Richter oder zumindest sehr viele waren politisch stark engagiert ${ }^{25}$. Meine Einstellung, meine Haltung wird ziemlich deutlich sichtbar an meinen Arbeiten, die ich während der Weimarer Republik geschrieben habe. Vor allem ergibt sie sich aus dem kleinen Buch, welches in Deutschland wieder erschienen ist und wesentlich aus dem Aufsatz, den ich für beinahe wichtiger halte, und der im Archiv für Sozialwissenschaften 1932 kurz vor Toresschluß erschienen ist. Daraus ist ersichtlich, daß ich als Jurist einen lebendigen Anteil an gesellschaftlichen Problemen nahm - aber mein kritischer Ansatzpunkt war kein integral-marxistischer, sondern ein demokratischer. Ich möchte noch einmal betonen, daß, wie ich immer wieder gesagt habe, meine Wiege nicht weit von der Paulskirche in Frankfurt gestanden hat. Und ich habe mich immer in dieser Beziehung als einen im mehr amerikanischen als vielleicht im deutschen Sinn als einen Liberalen empfunden, mit einem kleinen 1. Für mich hatte der Gedanke der individuellen Freiheit mehr Bedeutung als für meine stärker marxistisch orientierten Freunde in der damaligen Zeit.

22 Deutscher Baugewerksbund; Gewerkschaft der Bauarbeiter Deutschlands im ADGB in der Weimarer Republik.

23 Akademie der Arbeit; Bildungseinrichtung, primär für Arbeitnehmer, denen die herkömmliche Schulund Hochschulausbildung verwehrt worden war; gegründet 1921, der Frankfurter Universität angeschlossen; wesentliche Initiatoren waren Hugo Sinzheimer und Theodor Thomas; politische Zielsetzung u. a., die Diskrepanz zwischen Arbeiterbewegung und Weimarer Staat zu überwinden sowie über die Verbindung von Berufserfahrung und akademischer Ausbildung geschulte, gerade für Probleme der Arbeiterbewegung aufgeschlossene Funktionäre heranzubilden. Vgl. O. Antrick, Die Akademie der Arbeit in der Universität Frankfurt/M., 1966.

24 Afa-Bund (Allgemeiner freier Angestelltenbund); Dachorganisation der sozialdemokratisch ausgerichteten Angestelltengewerkschaften Deutschlands (1919-1933); 1. Vorsitzender von 1920-1933 war Siegfried Aufhäuser.

25 Dem einflußreichen "Preußischen Richterverein*, gegründet 1909, gehörten z. B. 1926 nach eigenen Angaben ca. 12000 Mitglieder an. Zentrales Organ war die "Deutsche Richterzeitung 
LUTHARDT: Welche Hoffnungen haben Sie insbesondere auf die wesentlich von Sinzheimer beeinflußten Artikel ISI-165 der Weimarer Verfassung gesetzt? Wie würden Sie das Verbältnis von Gewerkschaften und Räten beurteilen? Ich denke bier an die bekannte Formel von Georg Flatow, der die Betriebsräte einmal als *verlängerter Arm der Gewerkschaften * charakterisiert hat.

KAHN-FREUND: Hinsichtlich der Räte und ihrer Beziehung zu den Gewerkschaften muß man vom I. Allgemeinen Arbeiter- und Soldatenräte-Kongreß im Dezember 1918 in Berlin ausgehen ${ }^{26}$. Dort dankte nämlich der Arbeiter- und Soldatenrat zugunsten der Einberufung einer Nationalversammlung ab. Das Organ der Arbeiterklasse mußte zugunsten einer allgemeinen Nationalversammlung abdanken, denn die Ereignisse in Deutschland sind nicht zu verstehen, wenn man sie nicht außenpolitisch betrachtet. Die Hinwendung zu einer Rätediktatur hätte den unmittelbaren Weitermarsch der Entente-Truppen zur Folge gehabt. Das Gespenst des Bolschewismus hing über der Pariser Konferenz ${ }^{27}$. Nach dem Rätekongreß und der Einberufung der Nationalversammlung wurde der Ruf nach den Räten zu einem Oppositionsruf. Und hierher gehörte auch der von Sinzheimer formulierte Art. 165 der Verfassung. Fraenkel hat dies in seinem letzten Aufsatz ${ }^{28}$ dargestellt, d. h. die Einbettung dieses Rätegedankens in die demokratische Verfassungsstruktur und damit auch in das Gewerkschaftswesen. Dies gilt auch für die Formulierung von Flatow über die Betriebsräte als verlängerter Arm der Gewerkschaften ${ }^{29}$. Die Gewerkschaften haben sehr bald gemerkt, daß die Betriebsräte ein wunderbares Instrument der Gewerkschaften sein können und es auch wurden. Nicht überall, aber häufig, vor allem in den großen Betrieben, haben die Gewerkschaften, der ADGB, die Betriebsräte in der Regel beherrscht. Zu der Zeit, als ich ein aktives Interesse an diesen Problemen entwickelte, war dieser Gegensatz zwischen Räten und Gewerkschaften eigentlich im wesentlichen überwunden. Die Tätigkeit, die z. B. Flatow ausgeübt hat, er war Referent im preußischen Handelsministerium und schrieb jenes Buch ${ }^{30}$, in welches er mich später als Mitverfasser hereingenommen hat ${ }^{31}$, stand in keiner Weise im Gegensatz zu der Politik des ADGB oder der Einzelgewerkschaften.

LUTHARDT: Wie würden Sie u. a. jene bemerkenswerte demokratisch-politische Toleranz beurteilen, wie sie Sinzheimer vertreten hat?

KAHN-FREUND: Wenn jemand wie Sinzheimer in der liberalen Tradition steht, in der ich auch stehe, so muß man sich natürlich für den Verfolgten einsetzen. In der Weimarer Republik richteten sich die Verfolgungen hauptsächlich gegen die äußersten linken Flügel. Deswegen setzte man sich für diese Menschen ein, auch wenn man nicht mit ihnen übereinstimmte. Das geht nicht ganz so weit wie der berühmte Ausspruch von Voltaire, der zu jemandem gesagt hatte: „Ich hasse alles was Sie sagen, aber ich bin bereit, dafür zu sterben, daß Sie es sagen können«. Dies war im Grunde genommen ein Teil der Einstellung von Sinzheimer zum linken Flügel. Im übrigen gab es zweifellos Problemfelder, in denen er mit dem linken Flügel der Partei übereinstimmte. Er war nicht so festgelegt. Sie dürfen ferner nicht vergessen, daß uns

\footnotetext{
26 Vgl. Allgemeiner Kongreß der Arbeiter- und Soldatenräte. Berlin 16. bis 21. Dez. 1918 (1919), Nachdruck 1973.

27 Pariser Konferenz; Beginn 18. Januar 1919 durch Treffen von Woodrow Wilson, Präsident der Vereinigten Staaten, Lloyd George, Ministerpräsident von Großbritannien und Georges Clemenceau, Ministerpräsident von Frankreich in Paris. Hierbei ging es um die Klärung der sich aus dem Krieg ergebenden Folgeprobleme, die in Gestalt der von den Alliierten gesetzten Friedensbedingungen (Versailler Vertrag) von dem den Krieg auslösenden Deutschen Reich erfüllt werden sollten. 28 Fraenkel, Rätemythos und soziale Selbstbestimmung, a. a. O.

29 Georg Flatow, in: Walter Kaskel $(\mathrm{Hg}$.), Koalitionen und Koalitionskampfmittel, 1925 , is 8 .

30 Betriebsrätegesetz vom 4. 2. 1920, erläuter von Georg Flatow, Berlin 1923 (II)

31 Georg Flatow / Otto Kahn-Freund, Kommentar zum Betriebsrätegesetz, Berlin 193 I (1 3 ).
} 
der Umfang der Zusammenarbeit zwischen Ebert ${ }^{32}$ und Groener ${ }^{33} \mathrm{z}$. B. nicht bewußt war. Wir wußten das ja nicht. Noske ${ }^{34}$ war - der später von vielen verteidigt wurde uns allen ein Greuel. Jedenfalls erklärt sich so z. T. die Einstellung von Sinzheimer. Er gehörte nicht zum linken Flügel. Er hat zu mir in späteren Jahren, ich kannte ihn am besten in der zweiten Hälfte der zwanziger Jahre, einmal im Gespräch eine begeisterte Lobeshymne auf die Labour-Party und Ramsey McDonald"s angestimmt. Das ist an sich etwas merkwürdig. Das war im Grunde genommen: »Ah, die LabourParty «!

Sehen Sie einmal, die Labour-Party hat nie eine Doktrin formuliert. Sie war nie marxistisch, sie hat sich überhaupt nicht auf eine Doktrin festgelegt. Ich habe sie oftmals mit der "Church of England " verglichen, in der man alle möglichen Ansichten, selbstverständlich innerhalb gewisser Grenzen, äußern kann. Was Sozialismus ist, hat die Labour-Party nie zu definieren versucht. Sie war eine Aktions- und ist eine Aktions-Partei. Die Festlegung auf eine Weltanschauung ist eine Sache, die es in ihr nicht gibt. Infolgedessen ist diese Begeisterung für die Labour-Party nicht - ich würde das nicht akzeptieren - eine Begeisterung für eine Partei, die eine pluralistische Doktrin angenommen hat, sondern eine Begeisterung für eine Partei, die überhaupt keine Doktrin besitzt. So könnte man das, was Sinzheimer meinte, als ein Heraussehnen aus dem Doktrinarismus, der in Deutschland sowohl auf der Linken wie auf der Rechten bestand, bezeichnen.

LUTHARDT: Im Gespräch haben Sie immer wieder auf England bezug genommen. Mich würde interessieren, Sie sind ja nach 1933 nach London an die LSE gegangen, um dort englisches Recht $z u$ studieren, ob Sie in diesem Zusammenhang auch Harold Laski kennengelernt haben. Ich frage deshalb nach Laski, weil das wenige, was ich von ihm einmal gelesen habe, mich doch beeindruckt hat.

KAHN-FREUND: Ich bin 1933 ausgewandert. Die Einzelheiten spielen im Augenblick gar keine Rolle. Die »London School of Economics $~^{3^{6}}$ kannte ich schon von meinem früheren Aufenthalt in England. Umgehend nach meiner Ankunft in London habe ich dann sofort dort angefangen, Recht zu studieren. Meine Frau und ich haben gleichzeitig damit begonnen, uns dem englischen Milieu anzupassen. Ich war von Beginn an der Ansicht, wenn ich Deutschland verlasse, verlasse ich Deutschland nicht als Emigrant, sondern als Immigrant. Das ist entscheidend.

Nun kommen wir auf Harold Laski ${ }^{37}$ zu sprechen. Ich hatte eine Vorlesung bei ihm I 928 gehört, als ich damals in England war. Er war ein glänzender Dozent. Zu Beginn habe ich mich intensiv auf das Recht konzentriert. Ich wollte englischer Jurist werden - und wurde es - und hatte zunächst nur sporadische Kontakte zu Harold Laski.

32 Ebert, Friedrich (1871-1925); Schriftführer des Sattlerverbandes; Redakteur in der Lokalredaktion der Bremer Bürgerzeitung; 1904 Parteitagspräsident; 1905 Sekretär im Parteivorstand der SPD; 1912 Reichstagsmitglied; 1913 Parteivorsitzender; 9. November 1918 Reichskanzler; zusammen mit Hugo Haase (USPD) Vorsitzender im Rat der Volksbeauftragten; vom I1. Februar I9I9 bis zu seinem Tode Reichspräsident.

33 Groener, Wilhelm (t867-r939); I 899 Hauptmann im Großen Generalstab; I9 I 5 Generalmajor; I 9 I 6 Chef des Kriegsamtes; 1918 Erster Generalquartiermeister; 1920-1923 Reichsverkehrsminister; 1928 Reichswehrminister; 193 I zusätzlich bis zu seinem Rücktritt Reichsinnenminister.

34 Noske, Gustav (1868-1946); 1893-1918 Schriftleiter verschiedener Zeitschriften; 1906-1918 Mitglied des Reichstages; Dezember 1918 Mitglied des Rates der Volksbeauftragten; zuständig für das Militärressort; federführend in der Niederschlagung der revolutionären Strömungen, in Verbindung mit den Freikorps, tätig; Februar 1919-März 1920 Reichswehrminister; nach dem Kapp-Putsch im März I920 erzwungener Rücktritt; ab 1920 bis 1933 Oberpräsident in Hannover.

35 MacDonald, Ramsey (1 866-1937); führender britischer Labour-Politiker der zwanziger Jahre; 1923/24 Prime Minister des ersten Labour-Kabinetts; 1929/31 Prime Minister des zweiten Labour-Kabinetts.

36 LSE (London School of Economics and Political Science); gegründet von der Fabian Society; namhafte Hochschule der Wirtschafts- und Sozialwissenschaften.

37 Laski, Harold J. (1893-1950); führender sozialistischer Theoretiker in Großbritannien; zeitweilig Vorsitzender der Labour-Party; Professor für Political Science an der LSE. 
Näher kennen lernte ich ihn eigentlich erst während des Krieges, als die School nach Cambridge evakuiert wurde und wir dort zusammen wohnten. Harold Laski war in seiner politisch-theoretischen Einstellung nie konsequent. Ursprünglich war er reiner Pluralist, vor allem in seinen Schriften um 1920 herum. Carl Schmitt ${ }^{38}$ hat dies gespürt. Laski wurde dann stark vom Marxismus beeinflußt, ohne jemals ein konsequenter Marxist zu sein. Auch bei Harold Laski war das liberale Element vorhanden und er hat es nie bestritten. Infolgedessen stand er, bei allen Sympathien, die er für Sowjet-Rußland hatte, zu der Zeit, als ich ihn kennenlernte, dieser Spielart von Kommunismus prinzipiell ablehnend gegenüber. Selbstverständlich gehörte Laski dem an, was man den linken Flügel der Labour-Party nannte. Aber er war nicht weltanschaulich festgelegt. Damals, als Franz Neumann mit ihm in Berührung kam, war die marxistische Seite von Laski vielleicht mehr prononciert, als sie es vorher und wahrscheinlich auch wieder nachher gewesen ist. Für Laski selbst hatte ich stets eine große menschliche Symphatie, vor allem wegen seines Mutes und seiner Generösität. Eines seiner besten Bücher ist übrigens meiner Meinung nach »The Rise of European Liberalism *.

LUTHARDT: Ich möchte nun auf das Verhältnis der Formeln vom »sozialen Rechtsstaat" und der "Wirtschaftsdemokratie " zueinander zu sprechen kommen. Meiner Ansicht nach scheint doch Neumann rechtspolitisch eine wesentlich ausdifferenziertere Analyse der Kombination von "sozialem Rechtsstaat * und "Wirtschaftsdemokratie vorgelegt zu haben als Heller, der in der Bundesrepublik als einer der rechtstheoretischen und -politischen Väter der Formel vom »sozialen Rechtsstaat * rezipiert worden ist.

KAHN-FREUND: Vergessen Sie hierbei nicht die verschiedenartigen Stellungen, die Hermann Heller ${ }^{39}$ und die Franz Neumann einnahmen. Heller spielte eine große Rolle für uns alle, denn er war ja schließlich Professor für Staatsrecht an der Universität in Berlin. Und er war der einzige in der Zunft des deutschen akademischen Betriebes, mit dem man vernünftig reden konnte. Verstehen Sie, was ich meine? Für Heller war es nicht erforderlich, eine ausführliche Begründung einer wirtschaftsdemokratischen Konzeption vorzulegen. Er war nicht der Berater des ADGB oder einer Einzelgewerkschaft. Hingegen stand Neumann in jeder Beziehung mitten in der Praxis. Die Wirtschaftsdemokratie ${ }^{40}$ paßte in das Gesamtbild seiner Einstellung damals gut hinein. Dies dürfte der Grund sein, weshalb Heller in der Konkretisierung seiner Idee des sozialen Rechtsstaates ${ }^{41}$ etwas weniger weit gehen konnte als Franz Neumann. Dieser war sozusagen Tag und Nacht in Kontakt mit den Gewerkschaftern und wurde immer wieder von ihnen gefragt: "Was sollen wir dann

38 Schmitt, Carl (geb. 1888); Staatsrechtslehrer; 1916 Privatdozent in Straßburg; 1921 o. Professor in Greifswald, 1922 in Bonn, 1926 an der Handelshochschule in Berlin, 1933 in Köln, danach Berlin; unter dem Nationalsozialismus Ernennung zum Preußischen Staatsrat, Mitglied der Akademie für Deutsches Recht, Reichsamtswalter der Fachgruppe Hochschullehrer im Bund nationalsozialistischer deutscher Juristen; 1933 bis 1936 Herausgeber der Deutschen-Juristen-Zeitung; nach 1933 Herausgeber der Schriftenreihe "Der Deutsche Staat der Gegenwart ; nach I94s Amtsenthebung; seitdem Privatgelehrter in Plettenberg.

39 Heller, Hermann (1891-1933); Habilitation 1920 in Kiel; aktive politische Tätigkeit - zusammen mit Gustav Radbruch - in Kiel gegen den Kapp-Putsch; Verhaftung und Verurteilung zum Tode durch die Putschisten; 1921 bis 1925 Tätigkeit in der Volkshochschulbewegung in Leipzig; 1926 bis 193 r Referent am Kaiser-Wilhelm-Institut für ausländisches öffentliches Recht und Völkerrecht; 1932 Professor in Berlin und 1932 o. Professor in Frankfurt; Emigration nach Madrid 1933.

40 Die zeitgenössische, programmatische Schrift ist: Fritz Naphtali (Hg.), Wirtschaftsdemokratie (I928), 1977 (4); weiteres zeitgenössisches Material in den Beiträgen von M. Schneider, Arbeitsbeschaffung und C. Stephan, Wirtschaftsdemokratie und Umbau der Wirtschaft, in: W. Luthardt (Hg.), Sozialdemokratische Arbeiterbewegung und Weimarer Republik, 2 Bde., 1978, Bd. x.

4 I Heller, Rechtsstaat oder Diktatur? (1929), in: ders., Gesammelte Schriften, 3 Bde., 1971, Bd. 2, 443 ff.; abgedruckt auch in: M. Tohidipur (Hg.), Der bürgerliche Rechtsstaat, 2 Bde., 1978, Bd. I, I59 ff. 
jetzt machen? « Für Heller stellte sich diese Frage so nicht. Seine Tätigkeit erstreckte sich wesentlich auf die Universität im damaligen Berlin. Und sein Seminar in Berlin in den Jahren 1928/29/30 - genau weiß ich das nicht mehr - war wirklich ein Kristallisationspunkt. Wir sind hingegangen und haben Referate gehalten. Ich habe dort Gedankengänge des später, I93 I, als Buch veröffentlichten »Sozialen Ideals des Reichsarbeitsgerichts « vorgetragen.

LUTHARDT: Ich möchte hier gerne einhaken. Sie haben eben davon gesprochen, daß Sie Gedankengänge Ibrer 193 I erschienenen Schrift im Seminar von Heller vorgetragen haben. Mich würde nun interessieren, wie Sie heute die dort vertretene Argumentation beurteilen, insbesondere auch unter Berücksichtigung der in den letzten fünfzehn Jabren feststellbaren beachtlichen Rezeption wesentlicher Grundzüge Ibrer damals vorgelegten Ansichten.

$K A H N-F R E U N D$ : Zunächst einmal möchte ich festhalten, daß die Argumentation selbst überspitzt und stark polemisch ausgerichtet gewesen ist. Das merk würdigste an dem Buch scheint mir zu sein, daß es von einem Richter geschrieben wurde. Das Buch hat damals einen starken Widerspruch hervorgerufen, aber keinerlei Wirkung ausgeübt und keinen Anklang gefunden. Heute habe ich den Eindruck, daß es jetzt in Deutschland einen stärkeren Einfluß im Hinblick auf die Auseinandersetzung mit der arbeitsrechtlichen Problematik der Weimarer Republik hat als damals. Wesentlich erschien mir damals an der Schrift die Methode. Und in der Beziehung, so glaube ich, kann man etwas für das Buch sagen. Denn die dort vorhandene Polemik - nicht nur die offensichtliche gegen das Reichsarbeitsgericht -, sondern die Polemik gegen die Art und Weise, wie die herrschende Rechtswissenschaft sich mit dem Recht befaßt hatte. Nämlich ohne jeden Versuch der Herausarbeitung der ideologischen Hintergründe der Rechtsprechung. Und dies ist das, was ich eigentlich wollte und was ich heute noch will. Obwohl mein Vergleich mit dem Faschismus überspitzt war. Heute würde ich das selbstverständlich nicht mehr so schreiben. Aber, was die Methode betrifft, so habe ich auch heute noch nichts gegen das Buch einzuwenden. Um noch einmal auf die Aufnahme zurückzukommen. Die Resonanz war da, weitgehend jedoch negativ. Es gab natürlich Zeitgenossen, die so deutlich nicht waren, wie Flatow, Fraenkel, Suhr oder Neumann ${ }^{42}$. Da wurde gleich gesagt, das ist überspitzt, aber sie haben es akzeptiert. Sinzheimer hat das Buch gut gefallen. Wenn Sinzheimer mir nicht geholfen hätte, hätte ich auch keinen Verleger gefunden. Er hat die Drucklegung für mich vermittelt ${ }^{43}$. Der Herr Nörpel ${ }^{44}$, ein unwürdiger Repräsentant der Gewerkschaft - aber vielleicht war seine Reaktion nicht untypisch für die des

42 Vgl. die Besprechungen von Hugo Marx, in: Die Gesellschaft, Jg. VIII/r 931, Bd. 2, 569 ff.; Ernst Fraenkel, in: Die Justiz, Bd. 7, 193 1/32, 46 f. (= Fraenkel, Chronik, Anfang 193 r, in: Sinzheimer/Fraenkel, Die Justiz in der Weimarer Republik, $328 \mathrm{ff}$., $33 \mathrm{Iff}$.) mit methodischer Kritik an der von Kahn-Freund vorgenommenen Analogie zwischen dem geschriebenen faschistischen Gesetz und der deutschen Reichsgerichtsrechtsprechung. Positiv rezipiert - allerdings ohne die von Kahn-Freund vorgenommene Analogie - wurde die Schrift u. a. von Fraenkel, Die Krise des Rechtsstaats und die Justiz (193 I), in: ders., Zur Soziologie der Klassenjusitz und Aufsätze zur Verfassungskrise, 42 ff. (46 f.); Neumann, Koalitionsfreiheit und Reichsverfassung, 1932, 53 f.; ablehnende Besprechungen erfolgten in: Frankfurter Zeitung, 19. Juli 193 I; Arbeitsrecht, Jg. 18/r93 1, 539 ff.; Arbeitsgericht, Jg. 36/1931, 459; Archiv für civilistische Praxis, Jg. I6, 353; Reichsarbeitsblatt, Nichtamtlicher Teil, Jg. II, 634. Neumann, Die Herrschaft des Gesetzes (1936), 1980, 332, bezog sich auch nach 1933 positiv auf diese Schrift.

43 Vgl. M. Martiny, Integration oder Konfrontation, 1976, I 34.

44 Nörpel, Clemens (1885-1945); 1920-1933 mit Fritz Brolat Leiter der gemeinsamen Betriebsrätezentrale des ADGB und des Afa-Bundes; führender Arbeitsrechtler des ADGB in der Weimarer Republik; Referent auf dem r. Betriebsrätekongreß Okt. I 920 über die "Aufgaben der Betriebsräte «; Referent auf dem $r$. Bundeskongreß des ADGB 1922 in Leipzig über *Gewerkschaften und Betriebsräte «; Referent auf dem Kongreß des ADGB im Sept. I 93 I über »Entwicklung und Ausbau des Arbeitsrechts ; Referent auf der Betriebsrätekonferenz des ADGB und des Afa-Bundes in Berlin am 22. Januar 1933 zur Vorbereitung der Betriebsrätewahlen über Die Betriebsräte in der Wirtschaftskrise «; Herausgeber der Zeitschrift »Arbeitsrechts-Praxis $\propto$; ehrenamtlicher Arbeitsrichter am Reichsarbeitsgericht in Leipzig. 
normalen Gewerkschafters ${ }^{4}$ - wollte den Druck verhindern. Die Arbeitgeber haben zunächst nicht reagiert und erst später gab es dann eine Polemik in der ArbeitgeberVerbandszeitschrift. Ich stand in einer Oppositionsstellung gegen das Reichsarbeitsgericht und vor allem gegen den akademischen Betrieb des Arbeitsrechts.

Ich habe in der Arbeit einen großen Fehler gemacht. Ich habe nämlich - um einmal Ihren Ausdruck zu benutzen - das politische Selbstverständnis der Richter überschätzt. Es kann keine Rede davon sein, daß die Richter bewußt das faschistische Sozialideal verwirklicht haben. Und wenn ich dies formuliert habe, so war dies einfach ein Fehler. Die Richter selbst haben wahrscheinlich zum großen Teil von der „Carta del Lavoro ${ }^{46}$ und von dem faschistischen Gewerkschaftsgesetz vom April $1926^{47}$ überhaupt nichts gewußt. Es handelte sich bei ihnen auch gar nicht um eine klassenmäßige Selbstverteidigung, sondern um einen primitiven Widerstand gegen die Machtprätention der Gewerkschaften, die im Wesen der Bürokratie liegt. Ich meine, dieser Widerstand liegt im Wesen der Bürokratie, besonders der richterlichen Bürokratie. Und in diesen Zusammenhang gehörte der von mir festgestellte Umstand, daß ihre Einstellung gegenüber der individuell-arbeitsrechtlichen Schutzgesetzgebung durchaus positiv war. Wenn ich dies heute noch einmal zu schreiben hätte, würde ich es vollkommen anders formulieren. Ich würde auf keinen Fall von einer bewußten Imitation sprechen oder gar einem bewußten Sozialideal, sondern von einer Parallelität der Vorgänge, die gesellschaftlich begründet ist. D. h., der subjektive Faktor ist in diesem Buch, und dies ist das Anfechtbare daran, übertrieben. Der objektive Faktor ist nicht genügend ausgewertet. Dies ist meine Einstellung heute, nach einem halben Jahrhundert. Die Idee, daß die Richter ein bewußtes Sozialideal zum Ausdruck gebracht hätten, erscheint mir heute widersinnig.

LUTHARDT: Ich möcbte nun auf die Problematik des Art. I6s der Weimarer Verfassung $z u$ sprechen kommen. In diesem ist ja bekanntlich die Parität der Organisationen von Lohnarbeit und Kapital, d.h. der Gewerkschaften und der Unternehmer, verfassungsrechtlich normiert worden. Dieser Tatbestand ging in hervorragender Weise auf Sinzheimer zurück. Wie würden Sie die im Art. I6s angelegte Problematik beurteilen? Ich denke bierbei auch an den später von Fraenkel in diesem Zusammenbang benutzten Begriff des Pluralismus.

KAHN-FREUND: Mit Art. 165 der Weimarer Verfassung berühren Sie den wundesten Punkt der Verfassung. Hierzu gab es zwei Haltungen, zumindest zwei, wahrscheinlich mehr. Zwei vermag ich im Augenblick zu formulieren. Sie widersprachen sich, und, offen gesagt, wir alle sind zwischen ihnen niemals zu einer klaren

45 Vgl. die scharfe Kritik von Nörpel, Ein „Sozialideal« des Reichsarbeitsgerichts, in: Die Arbeit, Jg. VIII/193I, 56r ff. Nörpel hatte mit allen Mitteln versucht, die Veröffentlichung der Arbeit von Kahn-Freund zu verhindern. In einem persönlich an Kahn-Freund gerichteten Brief riet er diesem, von sich aus auf die Veröffentlichung zu verzichten. Zugleich informierte er Sinzheimer, Flatow, Fraenkel und Neumann. Als dies zu keinem Erfolg führte, hielt er es darüber hinaus für angebracht, sich in persönlichen Schreiben an die bekanntesten bürgerlichen Arbeitsrechtler - u. a. Jacobi/Leipzig, Hueck/Jena, Nipperdey/Köln, Molitor/Greifswald - von der Arbeit zu distanzieren. Vgl. Martiny, Integration oder Konfrontation, $134 \mathrm{f}$.

46 Carta del Lavoro; italienisches faschistisches Arbeitsgesetzbuch, proklamiert am 2r. April r927; es baute den stato corporativo weiter aus. Von sozialdemokratischer Seite wurde die ideologische Funktion dieses *Gesetzes« umgehend herausgearbeitet. Vgl. Ernst Fraenkel, Die Carta del Lavoro, in: BetriebsräteZeitschrift, Jg. 8/Nr. 10/14. Mai 1927, 289 ff.; vgl. auch Hermann Heller, Europa und der Faschismus (r929/r931), in: ders., Gesammelte Schriften, Bd. 2, 463 ff. ( 572 ff.). Fraenkel gibt an, daß die Carta del Lavoro umgehend in der Zeitschrift der Vereinigung Deutscher Arbeitgeberverbände, "Der Arbeitgeber « (1. Mai 1927), abgedruckt worden sei.

47 Gewerkschaftsgesetz; proklamiert am 3. April 1926. Wesentlicher Bestandteil des stato corporativo. Vgl. Heller, Europa und der Faschismus, $574 \mathrm{ff}$. sowie die Arbeit von Kahn-Freund, Das soziale Ideal des Reichsarbeitsgerichts; Franz Neumann, Die Gewerkschaften in der Demokratie und in der Diktatur, in: ders., Wirtschaft, Staat, Demokratie, 145 ff. (190 ff.), sowohl zur Carta als auch zum Gewerkschaftsgesetz. 
Entscheidung gekommen. Mein guter Freund Richard Joachim ${ }^{4}$, Ministerialrat im Reichsarbeitsministerium, nach 1933 von den Nationalsozialisten ermordet, sagte einmal, überpointiert im Gespräch, jeder, der beim Art. 165 stehen bleibt und ihn nicht als Durchgangspunkt ansieht, ist ein Faschist. Denn der bejaht den korporativen Staat. Das war sehr stark übertrieben gedacht und ausgesprochen, selbstverständlich nicht geschrieben. Andererseits stellte sich die Frage, auf die es innerhalb des sozialdemokratischen Bereichs der Weimarer Republik nur schwerlich eine Antwort gab. Wenn er einen Durchgangspunkt darstellt, einen Durchgangspunkt wohin? Was steht am Ende? Wohin marschieren wir, wohin wollen wir marschieren? Wir waren alle so verstrickt in entweder die politischen Tagesereignisse oder administrative oder juristische Probleme, daß wir es im Grunde genommen nie gewagt haben, diese Frage zu beantworten. Wir waren keine Kommunisten, und es wäre sehr schwierig gewesen, für irgendeinen von uns zu sagen, daß er die Diktatur des Proletariats wollte. Der Begriff des Pluralismus, den wir nur als einen polemischen Punkt aus den Schriften von Carl Schmitt ${ }^{49}$ her kannten, ist eine bequeme Formel, das ist die Fraenkelsche Formel ${ }^{50}$, um einen Ausweg aus diesem Dilemma zu finden.

LUTHARDT: In gewisser Verlängerung der eben formulierten Fragen würde ich gerne auf das Kollektive Arbeitsrecht $\mathrm{zu}$ sprechen kommen. Eine Verbindung ist meines Erachtens alleine schon dadurch gegeben, da beide in ibren strategischen Grundannabmen auf einem, ich will es einmal sehr allgemein sagen, relativen Gleichgewicht der Klassenkräfte berubten. Konnte man in der Tat das Kollektive Arbeitsrecht als "Prunkstück der Republik * charakterisieren, um den Ausdruck von Fraenkel zu verwenden?

KAHN-FREUND: Die Sache mit dem Kollektiven Arbeitsrecht in seiner allgemeinen Form muß von der Spezialsituation der Weimarer Republik unterschieden werden. Die Spezialsituation der Weimarer Republik war die Katastrophe der Massenarbeitslosigkeit, die auf den Zusammenbruch der DANAT-Bank ${ }^{\text {s1 }}$, faktisch auf den Schwarzen Freitag in Amerika, im Jahre 1929, folgte. Verbunden damit war, ein wesentlicher Punkt, die deflationistische Wirtschaftspolitik von Brüning ${ }^{52}$, deren Bedeutung nicht zu unterschätzen ist, nämlich der bewußte Versuch, durch Niedrighaltung der Löhne die Exportleistung Deutschlands wiederherzustellen. Was immer man von dem Kollektiven Arbeitsrecht im allgemeinen halten will, mit dem Einsetzen der Millionen-Arbeitslosigkeit und der deflationistischen Wirtschafts- und Finanzpolitik Brünings war das Kollektive Arbeitsrecht in Deutschland gescheitert. Denn das Kollektive Arbeitsrecht setzt u. a. ein gewisses Gleichgewicht der Kräfte voraus. Ein Gleichgewicht zwischen den Repräsentanten der Arbeiterbewegung und den Repräsentanten der Arbeitgeber. Dieses Gleichgewicht war durch die Massenarbeitslosigkeit vollkommen zerstört und damit waren die Gewerkschaften der zur

48 Joachim, Richard; Ministerialrat im Reichsarbeitsministerium; nähere Angaben konnten leider nicht ermittelt werden.

49 Vgl. Schmitt, Die geistesgeschichtliche Lage des heutigen Parlamentarismus (1923), 1969 (4), 89; ders., Der Begriff des Politischen (1932), 1963, 4 I ff.; ders., der Hüter der Verfassung (1931), 1969 (2), 87 ff.

$50 \mathrm{Vgl}$. Fraenkel, Deutschland und die westlichen Demokratien, z. B. $197 \mathrm{ff}$.

5I DANAT-Bank; 1922 entstanden aus der Fusion der Darmstädter Bank für Handel und Industrie und der Nationalbank für Deutschland zur Darmstädter und Nationalbank (DANAT-Bank); auf dem Höhepunkt der Bankenkrise im Juli 193 I mußte die DANAT-Bank ihre Zahlungsunfähigkeit bekanntgeben.

\$2 Brüning, Heinrich (1885-1970); Kriegsfreiwilliger; 1919 Referent von Adam Stegerwald; Ende r920 Geschäftsführer des christlichen Deutschen Gewerkschaftsbundes; seit 1924 Reichstagsabgeordneter des Zentrums; 1929 Fraktionsführer; ab 30. März 1930 Reichskanzler, Präsidialregierung unter extensiver Nutzung des Art. 48 WV zwecks Umsetzung von Notverordnungen; 1931 bis zu seiner Entlassung im Mai 1932 zugleich Reichsaußenminister; Anfang 1933 Vorsitzender des Zentrums, löst dieses am 5. Juli 1933 auf; 1934 Emigration; 1939 bis 1952 Lehrstuhlinhaber für Staatsverwaltung an der Harvard University/USA; I952 bis zu seiner Emeritierung o. Professor für Politische Wissenschaft in Köln. 
Aufrechterhaltung des Kollektiven Arbeitsrechts notwendigen Macht beraubt. Deswegen mußte alles herumschustern und herumdoktern am Kollektiven Arbeitsrecht und z. B. auch die Art und Weise der Argumentation, die ich in dem Aufsatz im "Archiv für Sozialwissenschaft" vorgebracht habe, an dem entscheidenden Punkt vorbei greifen. Denn der entscheidende Punkt war, daß die im Weimarer System und im Kollektiven Arbeitsrecht stillschweigend vorausgesetzte wirtschaftliche Situation des Gleichgewichts der Kräfte zerstört worden war. Dies scheint mir der Hauptgesichtspunkt zu sein.

Bezogen auf die von Ihnen angeführte Formel vom Kollektiven Arbeitsrecht als dem Prunkstück der Weimarer Republik kann man verschiedener Ansicht sein. Es gibt vermutlich Zeitgenossen, die sagen würden, was die Republik im Bildungswesen oder im Wohnungswesen erreicht hat, ist mindestens ebenso wichtig. Das ist eine Frage, über die man eigentlich gar nicht streiten kann, denn es ist eine Frage der subjektiven Wertung, für die es keine objektiven Maßstäbe gibt. Fraenkels Formel's liest sich gut, und warum nicht? Meine Einstellung zum Kollektiven Arbeitsrecht habe ich in dem englischen Buch über das Arbeitsrecht niedergelegt. Daraus geht hervor, daß nach meiner Ansicht die Erzeugung von Normen, nicht notwendigerweise rechtlichen Normen, durch das Zusammenspiel kollektiver Kräfte, so wie Sinzheimer dies verstanden hat, eine in unserer Gesellschaft nicht nur mögliche, sondern wünschenswerte und zweckmäßige Gestaltung der Lohn- und Arbeitsbedingungen ist.

Ich komme noch einmal auf die vorhin angesprochene Problematik des Durchgangspunktes zurück. Diese Frage nach dem Durchgangspunkt ist die Gretchenfrage, auf die jeder von uns eine ebenso ausweichende Antwort gegeben hätte wie Faust auf die Frage Gretchens, wie hältst du es mit deiner Religion. Denn hier mußte man Farbe bekennen und dazu waren wir nicht in der Lage, weil wir uns über die Bedingtheit unserer Situation und das Problem des Sozialismus - sagen wir es rundheraus - und das Verhältnis zwischen Demokratie und Sozialismus nicht im klaren waren. Wenn jemand das zu mir gesagt hätte, was ich eben zu Ihnen über das Kräftegleichgewicht sagte, so hätte ich vielleicht damals protestiert und gesagt, daß das eine unhaltbare Position sei und daß schließlich die Arbeiterklasse an die Macht kommen muß. Ob das mehr gewesen wäre als ein Lippenbekenntnis, bin ich heute nicht mehr in der Lage zu beantworten.

Man kann sagen, daß wir alle in dem gelebt haben, was man ein Narrenparadies nennt - a fool's paradise. D. h., wir befanden uns vollkommen im Irrtum über die wirklichen Machtpositionen. Wir wußten gar nicht, was eigentlich vorging. Wir hatten keine Ahnung davon, in welchem Umfang das, was man in Amerika den "military industrial complex nennt, schon die Weimarer Republik beherrschte. Ohne den wäre Hitler unvorstellbar gewesen. Dessen Produkt war er ja. Und infolgedessen war das ganze Gebäude, welches wir uns errichtet hatten, wenn Sie so wollen, ein Kartenhaus. Denn es war errichtet ohne Berücksichtigung der wirklichen Machtlage. Wir haben die Macht der Gewerkschaften in der Weimarer Republik weit überschätzt und die Macht der Reichswehr erheblich unterschätzt. Wir wußten es damals nicht. Unsere Ignoranz war vielleicht entschuldbar, vielleicht war sie es nicht, aber jedenfalls, sie war da.

LUTHARDT: Wie würden Sie die innere Ausböblung des Staates kennzeichnen?

53 Vgl. Fraenkel, Die politische Bedeutung des Arbeitsrechts(1932), in: ders., Reformismus und Pluralismus, 60 ff. (66); vgl. der Tendenz nach ders., Das Arbeitsrecht - ein Erfolg der Gewerkschaften, in: Metallarbeiter-Zeitung, Jg. 49/Nr. 22, 30. Mai 1931, 174 (Sondernummer: 40 Jahre DMV). 
KAHN-FREUND: Ich habe mich nicht ausführlich mit diesem Problem beschäftigt. Ich glaube, daß wir einfach nicht Bescheid wußten, daß wir über die Tatsachen nicht informiert waren. Möglicherweise war das, was in den späteren Jahren der Weimarer Republik als der Staat erschien, vielleicht nur noch der Mantel für etwas, was wir gar nicht sehen konnten. Ich kann dies nicht aus meiner Erfahrung sagen, aber ich habe diesen Eindruck.

LUTHARDT: Mich würden nun Ibre Erfabrungen als Richter interessieren. Saben Sie eine Möglichkeit, über die Rechtsprechung Teilerfolge für die Arbeitnebmer oder gar insgesamt für die Arbeiterbewegung zu erzielen?

$K A H N-F R E U N D$ : Wahrscheinlich habe ich zu bestimmten Zeiten gewisse Illusionen über die Möglichkeiten gehabt, über die Tätigkeit der Gerichte etwas zur Herstellung dessen beizutragen, was ich heute als Äquilibrium bezeichnen würde. Damals hätte ich es so nicht formuliert. Ich war mir darüber klar, ich mußte es ja sein, daß ich im Bereich derjenigen Fälle, die zu mir kamen, nur wenig tun konnte. Ich unterlag schließlich der Berufung. Außerdem waren die bei weitem überwiegende Zahl der Fälle, mit denen ich und jeder andere Vorsitzende am Arbeitsgericht beschäftigt waren, Fälle des individuellen Arbeitsrechts. Mit zunehmender Wirtschaftskrise überwiegen Fälle von Entlassungen und Einspruchs wegen unbilliger Härte aufgrund des Betriebsrätegesetzes ${ }^{54}$. Das war unser tägliches Brot. Da bestand die Möglichkeit, dem Individuum bis zu einem bestimmten Grade zu helfen. Ich habe es als meine Aufgabe angesehen, wie das im Gesetz auch vorgesehen war, so weit wie möglich einen Vergleich zwischen den Parteien herbeizuführen. Darüber habe ich sogar einmal einen Aufsatz in der "Juristischen Wochenschrift " 1930 geschrieben". In ihm schrieb ich über die soziale und prozessuale Bedeutung des arbeitsgerichtlichen Güteverfahrens und die Realisierung von Zielsetzungen, die durch Druck auf die Parteien seitens des Vorsitzenden möglich seien. Aber ich war auch der Auffassung, daß u. U. die Rechtsprechung wirklich zur Milderung der Situation beitragen konnte. Auch zu einer Zeit noch, als ich wahrscheinlich über die allgemeine Bedeutung der Rechtsprechung schon skeptischer gewesen bin als am Anfang.

Meine richterliche Tätigkeit fing im Herbst 1928 am Landgericht II in Berlin an. Schon im Januar 1929 arbeitete ich am Arbeitsgericht, teilweise infolge des Einflusses von Georg Flatow über das Ministerium. Ich wollte da etwas bewirken. Vielleicht ist es mir auch ein wenig gelungen. Aber in dem Zusammenhang der großen politischen Begebenheiten, über die wir eben gesprochen haben, was hat das schon ausgemacht. Da hilft man einmal jemandem, damit er einige Tausend Mark erhält. Rückblickend muß ich sagen, daß, wenn ich Illusionen hatte, diese im Laufe der Zeit wahrscheinlich abgenommen haben. Ich erinnere mich an eine Begebenheit. Ich galt als gewerkschaftsfreundlich und war nicht sehr beliebt bei den Arbeitgebern, besonders nicht bei dem Verband Berliner Metallindustrieller, mit dem ich viel zu tun hatte. Der Syndikus, der ständige Rechtsberater der Berliner Metallindustriellen namens Stephan Oppenheimer ${ }^{56}$, Fraenkel kannte ihn gut, sie trafen sich häufig am Landesarbeitsgericht, sagte einmal zu ihm etwas, was Fraenkel mir wiederholt hat: Oppenheimer sagte, ich wollte reformieren, die Gesellschaft reformieren. Dagegen

\$4 Vgl. die konkret-juristischen Analysen von Otto Kahn-Freund: Die Rechtslage während der Kündigungsfrist bei ungerechtfertigter fristloser Kündigung, in: Arbeitsrechts-Praxis, Jg. 1929, H. 6/Juni 1929, I2I ff. In einem anderen Kontext Kahn-Freund, Kranken- und Mutterschutz nach geltendem Recht und nach dem Entwurf eines Hausgehilfengesetzes, in: Arbeitsrecht, Jg. XVI, H. I I/Nov. 1929, Sp. 62 I ff. und ebda., H. I $2 /$ Dez. I929, Sp. $707 \mathrm{ff}$.

ss Otto Kahn-Freund, Die prozessuale und soziale Funktion des arbeitsgerichtlichen Güteverfahrens, in: Juristische Wochenschrift, Jg. $59,1930, \mathrm{Bd} . \mathrm{I}, \mathrm{H} .6,388 \mathrm{ff}$.

s6 Oppenheimer, Stephan; nähere Angaben konnten leider nicht ermittelt werden. 
hätte er, Oppenheimer nichts, nur könne man dies nicht, wie er es ausdrückte, aus dem Froschteich des Arbeitsgerichts tun. Oppenheimer hatte vollständig recht. LUTHARDT: Ich möchte hier einmal gerne kurz einhaken. Angesichts der nun im Durchschnitt eindeutig gegen die Arbeiterbewegung eingestellten Justiz, dies ergibt sich m. E. gerade aus einer ganzen Reibe sozialdemokratischer Arbeiten zu diesem Tatbestand, wäre es da nicht vielleicht politisch sinnvoller gewesen, in der sog. Entscheidungsphase zu Beginn der Republik für eine bestimmte Zeit die verfassungsmäßig normierte richterliche Unabhängigkeit aufzuheben und politisch die Justiz zu demokratisieren? Ich meine damit die Möglichkeit, die tradierte, konservativ eingestellte Richterschicht zumindest in Teilen aufzubrechen.

$K A H N-F R E U N D$ : Ich persönlich glaube daran nicht. Was bedeutet die Aufhebung der richterlichen Unabhängigkeit? Sie bedeutet, daß in bestimmten Situationen eine politische Instanz, die dem Parlament in einer parlamentarischen Demokratie wie der Weimarer Republik verantwortlich ist, einem Gericht Instruktionen darüber zu geben vermag, wie es zu urteilen hat. Wie hätte eine solche Instanz in der Weimarer Republik ausgesehen? So etwas hätte man sich in den allerersten Monaten vorstellen können, nicht daß ich es gebilligt hätte. Schon mit dem Zusammentritt der Nationalversammlung im Jahre 1919 war die Regierung eine Koalitionsregierung. Die Aufhebung der richterlichen Unabhängigkeit hätte also darin bestanden, daß an die Stelle des Richterspruchs ein politischer Kompromiß getreten wäre. Dies wäre meiner Ansicht nach eine verhängnisvolle Sache gewesen. Hinzu kommt jedoch noch etwas anders. Dies bezieht sich auf das Wesen des richterlichen Urteils. Der Adressat des Zivilurteils ist die Partei, die den Prozeß verliert. Der Adressat des Strafurteils ist der Angeklagte, der Verurteilte, der zu einer Geldstrafe oder zu einer Gefängnisstrafe verurteilt wird. Für die Kohäsion eines Staatswesens ist es meiner Meinung nach unumgänglich, daß dieser Vorgang als die Anwendung von vorgegebenen Normen erklärt wird, nicht als eine ad hoc-Entscheidung, sonst würde sie moralisch unerträglich. Dies ist die psychologische Rechtfertigung der richterlichen Unabhängigkeit.

Uber das Richtertum in Deutschland ist viel geschrieben worden. Es gibt u. a. das ausgezeichnete Buch von Dessauer ${ }^{57}$, "Recht, Richtertum und Ministerialbürokratie « $^{8}$. Fraenkel, Neumann u. a. haben darüber gearbeitet. Die Grundhaltung des Richtertums in der Weimarer Republik kann man nicht verstehen, wenn man übersieht, wieweit die aktiven, die amtierenden Richter in der Ideologie des Kaiserreichs erzogen wurden, als Studenten, beim Militär, jenes Prestige des Reserveleutnants. Ferner die Wirkung der Inflation auf die Klasse, aus der die Richter kamen. Und die vorgegebenen Vorurteile des Richtertums. Heute mögen dies Gemeinplätze sein, zur Erklärung der Tätigkeit der Justiz sind sie unumgänglich erforderlich. Notwendig gewesen wäre ein Revirement über die Erziehung, die Erziehung einer neuen Richtergeneration. Die Sozialdemokratie war hierfür viel zu schwach, die anderen Parteien hätten sich dem widersetzt. Unter einer Koalitionsregierung wäre dies ebensowenig möglich gewesen wie der Aufbau einer neuen Armee.

LUTHARDT: Als Vorsitzender Richter an einem Arbeitsgericht in Berlin waren Sie $a b 1929$ selbst an zablreichen Entscheidungen beteiligt. War es da durchaus opportun $z u$ hoffen, mittels Richterrechts im je konkreten Einzelfall positiv-rechtlich auf die Normen der Verfassung zurückzugreifen und so der herrschenden Tendenz entge-

57 Dessauer, Friedrich (1881-1963); Professor für Biophysik in Frankfurt; Zentrumspolitiker; Mitglied des Reichstages von 1924 bis 1933 ; Emigration 1933 in die Schweiz, später in die Türkei. s8 Dessauer, Recht, Richtertum und Ministerialbürokratie, Mannheim/Berlin/Leipzig 1928. 
genzuarbeiten? Ich meine damit, welche Funktion hat eigentlich die Verfassung als Staatsgrundgesetz der Gesellschaft für die Rechtsprechung, hier für einen konkreten Einzelfall?

KAHN-FREUND: Auf die Normen der Verfassung konnte man nur in bestimmten Fällen zurückgreifen. In der Weimarer Republik gab es im allgemeinen kein richterliches Prüfungsrecht durch die Justiz. Die Fragen der Verfassungsmäßigkeit von Gesetzen ergab sich nicht so wie heute in der Bundesrepublik, wo der Richter die Sache selbst an das Bundesverfassungsgericht verweisen kann. In Weimar konnte es sich also nur um die Interpretation von Gesetzen hinsichtlich ihrer Verfassungskonformität handeln oder um die Be- oder Verurteilung irgendwelchen Verhaltens. Es gab Fälle, wo man sich auf die Normen der Verfassung beziehen konnte. Der für mich entscheidende Fall, der Fall, der im Rückblick im Zentrum meines ganzen Gerichtserlebnisses steht, war der berühmte Radiofall. Ich weiß nicht, ob Sie davon wissen? Dann werde ich Ihnen den Fall erzählen. Ich habe nichts dagegen, ihn hier zu Papier zu bringen, ich wollte dies sowieso einmal tun.

Ich war Vorsitzender einer Kammer am Arbeitsgericht in Berlin, einer von mehr als fünfzig Richtern. Das Drama beginnt am 9. Februar 1933, etwas über eine Woche nachdem Hitler Reichskanzler geworden war. Es war der Tag, an dem Hitler zum ersten Male über den Rundfunk zum deutschen Volk sprach. Damals war es technisch noch nicht möglich, diese Rede vom Palais des Reichskanzlers zu halten. Herr Hitler mußte sich also in das Rundfunkgebäude begeben. Am Morgen dieses 9. Februar 1933 wurden drei leitende Angestellte der Reichsrundfunkgesellschaft mbH entlassen. Sie wurden nicht fristlos entlassen, man zahlte ihnen ihr Gehalt für die Kündigungsfrist, aber keine Entschädigung aufgrund des Betriebsrätegesetzes. Daraufhin erhoben sie Einspruch beim Betriebsrat, der diesem stattgab und danach Klage vor dem Arbeitsgericht. Verschiedene Kollegen drückten sich vor dem schwierigen Fall. Er kam dann zu mir. Juristisch handelte es sich um das Problem, ob die Reichsrundfunkgesellschaft im Sinne des damaligen $₫ 8$ s des Betriebsrätegesetzes als Tendenzbetrieb angesehen werden konnte. Es wurde vage angegeben, die Angestellten seien Kommunisten und im Hintergrund stand der nicht deutlich formulierte, aber doch angedeutete Verdacht der Sabotage. Sie fragten mich eben nach der Verfassung. In diesem Fall kam die Verfassung, nämlich Art. I 8 der Weimarer Verfassung - freie Meinungsäußerung - in Betracht. Ich habe ein eindeutiges Urteil gefällt und die Rundfunkgesellschaft zur maximalen Entschädigung verurteilt. Ich dürfte einer der letzten Personen gewesen sein, die noch in Deutschland ihre Meinung sagen konnten.

Später, nicht sehr viel später dann wurden die Kläger verhaftet, bis sie auf das Urteil verzichtet hatten. In Holland habe ich einen der Kläger wiedergesehen und er hat seiner Freude Ausdruck gegeben, daß ich in Freiheit geblieben und nicht verhaftet worden bin. Es war ein dramatischer Fall, die Verhandlung dauerte den ganzen Tag. Ich hatte wirklich die Möglichkeit, die Unabhängigkeit der Gerichte durch meine eigene Tätigkeit in diesem Augenblick zu bekunden.

Die Verfassung war noch im Hintergrund. Man konnte sich noch auf sie berufen. Auf den Art. I 8 in diesem Fall. Ferner spielte die Verfassung insofern eine Rolle, als in Art. I 59 die Koalitionsfreiheit normiert war. Man kann also nicht davon sprechen, daß die Weimarer Verfassung für die richterliche Tätigkeit bedeutungslos gewesen sei.

LUTHARDT: Welche Bedeutung hatten eigentlich obergerichtliche Entscheidungen? Bestand auch damals schon der Tatbestand, daß progressive untergerichtliche Entscheidungen sozusagen von den Obergerichten wieder zurückgenommen wurden, um meine letzte Frage $z$ formulieren? 
KAHN-FREUND: Dies gab es. Unter Umständen konnte es aber auch umgekehrt gewesen sein. Es konnte der Fall sein, man kann nicht generalisieren, daß eine regressive untergerichtliche Entscheidung vom Obergericht progressiv gedeutet wurde. Es gab Tendenzen, wie ich dies in meinem Buch damals darzulegen versucht habe, gerade im Reichsarbeitsgericht, die durchaus in diesem Sinne - was immer das bedeuten mag - progressiv gewesen sind, z. B. in der Auslegung gewisser Bestimmungen über Urlaub, Kündigungsfristen, Bezahlung während der Krankheit usw. Es war durchaus möglich, daß ein reaktionäres Landesarbeitsgericht eine Entscheidung vorgelegt hat, die später in Leipzig aufgehoben wurde. Eine Generalisierung ist nicht möglich. Wenn es sich hingegen um das kollektive Arbeitsrecht handelte, so war die Situation in etwa so, wie ich sie in meinem Buch versucht habe darzustellen. Es ist unmöglich, hier eine deutliche Unterscheidung zwischen den unteren und den oberen Gerichten vorzunehmen. Es gab zu viele Richter.

LUTHARDT: Herr Kabn-Freund, ich danke Ihnen recht herzlich für dieses Gespräch.

\section{Eine Auswabl umfangreicherer Werke von Otto Kabn-Freund}

Umfang der normativen Wirkung des Tarifvertrages und Wiedereinstellungsklausel (Diss. jur. Frankfurt 1925), Berlin 1928.

Das soziale Ideal des Reichsarbeitsgerichts, Mannheim $193 \mathrm{r}$.

wiederabgedruckt in:

a) Thilo Ramm (Hrsg.), Arbeitsrecht und Politik. Quellentexte 191 8-1933, Neuwied/ Berlin 1966.

b) Thomas Blanke, Rainer Erd, Ulrich Mückenberger, Ulrich Stascheit (Hrsg.), Kollektives Arbeitsrecht, 2 Bde. Reinbek/Hamburg 1975, Bd. I (gekürzt).

Germany and Europe. Workers Educational Association Study Outlines Nr. 2, 1940 (anonym erschienen).

Mitarbeit an: The next Germany. A basis of discussion on peace in Europe. A Penguin Special, London 1943.

Labour and the Law, $1977^{2}$; deutsch: Arbeit und Recht, Ubersetzung Franz Mestitz, Frankfurt/Köln 1979.

General Problems of Private International Law, 1976.

Selected Writings. Editorial Introduction by Martin Partington, London 1978 , Bibliography S. $374 \mathrm{ff}$.

Labour Relations: Heritage and Adjustment, 1979; deutsche Ubersetzung, von Franz Mestitz, im Druck.

Würdigungen

Bulletin of the International Law Society, No. I I, September 1971.

Franz Gamillscheg, Jean de Givry, Bob Hepple, Jean Verdier (Hrsg.), Gedächtnisschrift für Otto Kahn-Freund, München 198r.

Sir Otto Kahn-Freund, Q. C., F. B. A. 1900-1979, by B.(ob) A. H.(epple); The Study of Labour Law - Some Recollections, by Sir Otto Kahn-Freund, in: The Industrial Law Journal, December 1979, pp. 193-196; pp. 197-201. 